Original Article

\title{
A retrospective descriptive study on usage of Aerovac- an aerosol evacuating chamber for aerosol generating medical and surgical procedures.
}

\author{
DumingoarachchiG D. ${ }^{1}$, Dhanapala B A N. ${ }^{2}$,Wijesurendra W A B U. ${ }^{3}$, Rupasinghe R T ${ }^{4}$, \\ Udayani L A D..$^{5}$, ThelikoralaS. ${ }^{6}$, RathnayakeS S. ${ }^{7}$, UndugodageU C M ${ }^{8}$ \\ 1 - Consultant Otorhinolaryngologist \& head and neck surgeon Teaching Hospital Anuradhapura, Sri Lanka \\ 2 -Mechanical Engineer Department of Provincial Health, North Central Province Anuradhapura, Sri Lanka \\ ${ }^{3-}$ Biomedical Engineer, A Baurs and Company, Colombo Sri Lanka. \\ ${ }^{4-}$ Consultant Otorhinolaryngologist \& head and neck surgeon Teaching Hospital Anuradhapura \\ ${ }^{5-}$ Senior registrar in Otorhinolaryngology \& head and neck surgery Teaching Hospital Anuradhapura \\ ${ }^{6-}$ Registrar in in Otorhinolaryngology \& head and neck surgery Teaching Hospital Anuradhapura \\ ${ }^{7-}$ Nursing officer Teaching Hospital Anuradhapura \\ ${ }^{8-}$ Consultant Respiratory Physician \& Senior Lecturer, Faculty of Medical Sciences University of Sri \\ Jayewardenepura, Sri Lanka.
}

\section{Introduction-}

Many respiratory borne infections are transmitted to health care workers during aerosol generating procedures. A safe mechanism to conduct such procedures is important.

\section{Objective-}

To design a safe aerosol evacuation chamber to perform multiple aerosol generating procedures and to assess the practical use of it.

\section{Methodology -}

We designed an aerosol evacuation chamber with an exhaust mechanism, a novel cost-effective multipurpose chamber, which can be used to perform a number of aerosol generating procedures of the airways, upper gastrointestinal tract and the head and neck region, without exposing health care staff to aerosols. Exhaust from the chamber is filtered by a HEPA filter and is treated with UVG irradiation to destroy microorganisms prior to the release of air into the environment. Records of various ENT procedures performed using the Aerovac chamber was over a period of one year were retrospectively evaluated.

\section{Results-}

Total of 498 procedures had been carried out. Nasal endoscopy had been the most frequently carried out procedure. Most procedures were done under local anesthesia. There were no adverse events to patients or to health care workers reported.

\section{Conclusion -}

Aerovac chamber can be used to safely conduct multiple aerosol generating procedures.

\section{Keywords}

Aerosol, Chamber, COVID 19, Vacuum

Copyright: (C) 2021Dumingoarachchi et al.

This is an open access article distributed under the Creative Commons Attribution License (CC BY 4.0) (c) () long as they credit the original author for the creation.

Funding: None

Competing interest: None

Correspondence: Dr. G.D. Dumingoarachchi (gnanapriyaent@yahoo.com) 


\section{Background and introduction}

Published Date: $31^{\text {st }}$ December2021

Many specialties such as pulmonology, otorhinolaryngology, anesthesiology and gastroenterology routinely perform respiratory aerosol generating procedures (AGPs) and droplet inducing procedures $^{1,2}$. These include airway procedures (fiber-optic laryngoscopy, rigid nasal endoscopy, tracheostomy, bronchoscopy, endo-bronchial ultrasound), anesthetic procedures (intubation/extubation, bag mask ventilation) gastroenterological procedures (upper gastrointestinal endoscopy), LASER and drilling procedures of the ear, nose, throat region ${ }^{2}$. These procedures pose a high risk of contracting air borne infections such as COVID 19 and tuberculosis by the health care workers (HCWs) ${ }^{3}$.

Guidance issued by the World Health Organization on AGPs states, personal protective equipment (PPE) including air purifying respirator $(\mathrm{FFP} / 3$, ) is required when performing an AGP in a patient confirmed or suspected of having SARS CoV 2 infection ${ }^{4}$.

At present there is a substantial shortage of respirators (e.g. N95 masks) across the world, especially in the low-income countries. Fit testing for respirators is not routinely performed and the use of substandard masks have subjected HCWs to high risk of infection.

Another mechanism to reduce the risk of infection to HCWs is to perform AGPs in negative pressure rooms (air born infection isolation areas (AII). AII operating theaters ${ }^{3}$ are designed to prevent infection to HCWs. The contaminated air inside the room is continuously pumped out, while clean air flows into the room. This mechanism prevents contaminated air from seeping out of the room when the door is open as the air flow is always from outside to inside. Therefore, the HCWs working immediately outside the vicinity of the room are also protected from infection. Unfortunately, most of bronchoscopy /endoscopy rooms do not have negative pressure. Majority of the OTs in the world are positive pressure rooms. Positive pressure is maintained at OTs to prevent surgical site infections $(\mathrm{SSI})^{3}$ in patients. However, this can adversely affect HCWs in case of airborne infections. An example would be a patient with SARS CoV-2 infection undergoing an aerosol generating surgery in a positive pressure room (without the HCWs in adequate PPE or poorly fitted respirators), will lead to very high risk of infection to the HCWs. Constructing and maintenance of negative pressure ventilation rooms and operating theaters are expensive and time consuming.

In addition to COVID 19, there are many other respiratory borne infections that are transmitted to HCWs during AGPs. Tuberculosis is one such infection, especially in countries with a high- moderate burden of tuberculosis 5 .

Other described methods to protect health care workers from airborne infections are, barrier enclosure during endotracheal intubation, including aerosol boxes ${ }^{6,7}$ and the use of negative pressure tents for respiratory therapies ${ }^{8}$.

It has been demonstrated by previous studies that aerosol boxes without suction confer minimal to no benefit in containing aerosols during an aerosol-generating procedure. However sealed box with suction appears to decrease airborne particle exposure ${ }^{9}$.It has also been demonstrated that a $35 \mathrm{X} 45 \times 50$ $\mathrm{cm}$ chamber can be cleared of particles with a 0.14 minute half life with $60 \mathrm{CFM}$ vacuum ${ }^{10}$.It can be extrapolated that a device with dedicated vacuum exhaust function would effectively prevent operating theater room contamination by airborne particles.

\section{Methodology}


We designed a chamber made of stainless-steel frame and transparent polyacrylic surfaces (Aerovac). (Pending grant of patent - Priority claim reference no - LK/P/21139. 29 May 2020 and approved by the National Medicines Regulatory Authority). This can be fitted to the upper part of a standard theater bed and the chamber can be placed on the upper part of the patient's body. There are with multiple openings/ports around chamber to facilitate accessibility to the operator in order to perform the procedure. This chamber is attached to an exhaust mechanism. This exhaust system continuously sucks out air from the chamber. This process generates a pressure gradient across the chamber, thus there is a continuous flow of room air into the chamber. (Figure 1). The aerosols generated within the chamber flows out via an exhaust system. The exhaust from the chamber is filtered by a HEPA filter and is treated with UVG irradiation to destroy microorganisms prior to the release of air into the environment. The air in the chamber flows out at an approximate rate of 154 cubic feet per minute as measured by an anemometer. This rate is more than adequate to achieve minimum recommended 12 air changes per hour recommended by centers for disease control and prevention (CDC) in designing airborne infection isolation(AII) areas ${ }^{3}$. The absence of backflow of air from the chamber to the room protects the room air from contamination.

The integrity of the chamber was assessed using a smoke simulation test. A Laerdal airway management trainer manikin was placed inside the procedure chamber. A fog machine was connected to the lung tubes via a connector. The smoke emitting from the mouth of the manikin into the procedure chamber was recorded with the use of a high definition camera. The chamber was completely cleared of the fog and there was no visible leakage to the environment.

For disinfection, the chamber is cleaned with soap and water followed by wiping the surfaces with $70 \%$ alcohol. The detachable sides allow easy access for cleaning. For sterilization, the chamber can be dismantled and soaked in peracetic acid ${ }^{12}$.Stainless steel frame can be even autoclaved and can be wrapped with sterile polythene sheets to carry out sterile surgical procedures. We recommend the HEPA filter to be inspected every 6 months and replaced when flow (measured by anemometer) decreases by about $50 \%$.

We performed ENT and related AGP s using Aerovac chamber, at the Otorhinolaryngology and head and neck unit, Teaching Hospital Anuradhapura.

(Video -https://youtube.com/watch?v=xSVHyPgFpbs\&feature=share).

Incidence reporting on patient and/or operator safety on operating theater reports were retrospectively analyzed.

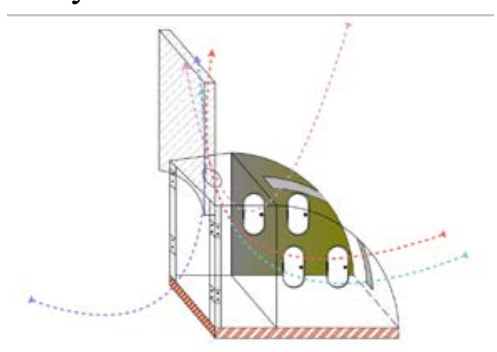

Figure 1 - Aerovac chamber depicting airflow 


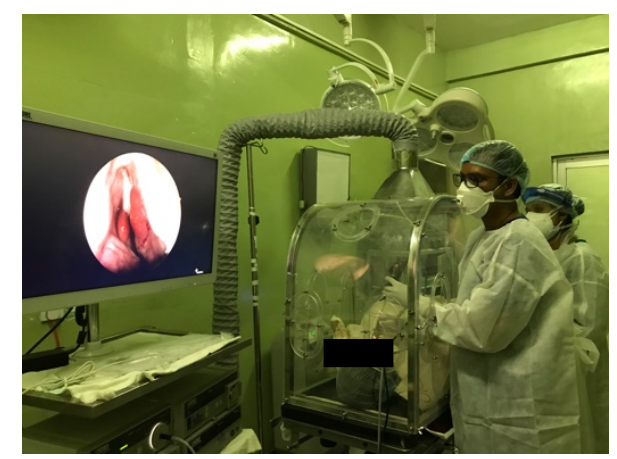

Image 1 - Performing a rigid nasal endoscopy using the Aerovac chamber

\section{Results}

A total of 498 procedures were performed using the Aerovac chamber over one year.. The procedures were rigid nasal endoscopy, endoscopic dacrocystorhinostomy, image guided endoscopic sinus surgery, endoscopic myringoplasty, flexible bronchoscopy with biopsy, intubation, direct laryngoscopy, tracheostomy and upper gastrointestinal endoscopy (UGIE) (table 1). Majority of the procedures were done under local anesthesia. $(n=477)$

\begin{tabular}{|l|l|l|l|}
\hline Procedure & Indication & $\begin{array}{l}\text { Type of } \\
\text { anesthesia }\end{array}$ & $\begin{array}{l}\text { Number } \\
\text { of cases }\end{array}$ \\
\hline Rigid nasal endoscopy & $\begin{array}{l}\text { Diagnostic } \\
\text { therapeutic }\end{array}$ & LA & 396 \\
\hline Otoendoscopy & mainly diagnostic & LA & 61 \\
\hline Endoscopic sinus surgery & therapeutic & GA & 12 \\
\hline Fibre-optic laryngoscopy & diagnostic & LA & 11 \\
\hline Endoscopic DCR & therapeutic & GA & 06 \\
\hline Endoscopic myringoplasty & therapeutic & LA & 05 \\
\hline Direct laryngoscopy and biopsy & diagnostic & GA & 02 \\
\hline Flexible bronchoscopy and biopsy & diagnostic & LA & 02 \\
\hline UGIE \& Biopsy & diagnostic & LA & 02 \\
\hline Tracheostomy & therapeutic & GA & 1 \\
\hline
\end{tabular}

Table1 Procedures carried out during four months from June 2020 to June2021

All procedures were carried out for the entire length of the time using the Aerovac chamber. There were no instances where the patient had to be evacuated from the chamber due to an emergency. Operators reported that rigid nasal endoscopy is the procedure that they are most comfortable to perform using the Aerovac chamber. This is also the commonest procedure performed. Procedures done under general anesthesia, required the chamber to be sterilized prior to each procedure which was time consuming. The restrictions on certain hand movements during general anesthesia posed technical difficulties. There were no reports of adverse effects. None of the patients had developed hypoxia or shortness of breath during procedures. One patient complained of claustrophobia.

\section{Discussion}

Aerosol generating procedures act as a source of infection to HCWs. COVID pandemic brought more focus on this issue, as many HCWs contracted COVID during the early stages of the pandemic. Many guidelines were developed both internationally and locally on the safety of AGPs. These included 
negative pressure rooms and PPE. In developing countries, the availability of negative pressure rooms and PPE are scarce. Thus, the need to look at alternative methods is important. There are several publications on methods to safely perform AGPs. Allen et al ${ }^{7}$ describes a procedure on the use of drape/ patient covering during AGP but this was only for anesthetic procedures and Fox et al ${ }^{8}$ describes a negative pressure tent and it is connected to the hospital wall suction system. Aerovac chamber is the first chamber to be developed with an integral exhaust system to perform multiple surgical and medical aerosol generating procedures and this is the first study done using a novel chamber. This study demonstrates that the above procedures can be done safely, without significant technical difficulty. To our knowledge this is the first study conducted for AGPs using a novel chamber. A limitation of this study is that the HCWs involved in performing the AGPs were not followed up with COVID PCR. The patient comfort was not assessed objectively.

\section{Conclusion}

Aerovac chamber can be used safely to perform multiple medical and surgical aerosol generating procedures.

\section{Reference}

1. Tran K, Cimon K, Severn M, Pessoa-Silva CL, Conly J. Aerosol generating procedures and risk of transmission of acute respiratory infections to healthcare workers: A systematic review. Vol. 7, PLoS ONE.2012.https://doi.org/10.1371/journal.pone.0035797. PMid:22563403 PMCid:PMC3338532

2. Cook T, Ferguson K, Johannsson H, Harrop-Griffiths W. Managing theatre processes for planned surgery between COVID-19 surges.

3. Department of Health US, Services H, for Disease Control C. Guidelines for Environmental Infection Control in Health-Care Facilities Recommendations of CDC and the Healthcare Infection Control Practices Advisory Committee (HICPAC). 2019.

4. Handbook of COVID-19 Prevention and Treatment Compiled According to Clinical Experience.

5. WORLD HEALTH ORGANIZATION. GLOBAL TUBERCULOSIS REPORT 2019. WORLD HEALTH ORGANIZATION; 2019.

6. More on Barrier Enclosure during Endotracheal Intubation. N Engl J Med [Internet]. 2020;382(21):e69. https://doi.org/10.1056/NEJMc2012960

7. Allen B, Gardner C, O'Neill C, Gibbs M. Use of drape/patient covering during potentially aerosolizing procedures. Am J Emerg Med. 2020 May; https://doi.org/10.1016/j.ajem.2020.05.007

PMid:32402501 PMCid:PMC7204666

8. Fox TH, Silverblatt M, Lacour A, deBoisblanc BP. Negative Pressure Tent to Reduce Exposure of Health Care Workers to SARS CoV-2 During Aerosol Generating Respiratory Therapies. Chest [Internet]. 2020 May 23; https://doi.org/10.1016/j.chest.2020.04.070. PMid:32454046 PMCid:PMC7245257

9. Simpson JP, Wong DN, Verco L, Carter R, Dzidowski M, Chan PY. Measurement of airborne particle exposure during simulated tracheal intubation using various proposed aerosol containment devices during the COVID-19 pandemic. Anaesthesia. 2020 Jun 19; https://doi.org/10.1111/anae.15188. PMid:32559315 PMCid:PMC7323428 
10. Lang AL, Shaw KM, Lozano R, Wang J. Effectiveness of a negative-pressure patient isolation hood shown using particle count. Vol. 125, British Journal of Anaesthesia. Elsevier Ltd; $\quad 2020 . \quad$ p.e295-6.https://doi.org/10.1016/j.bja.2020.05.002.PMid:32419700 PMCid:PMC7225719

11. WHO. Severe Acute Respiratory Infections Treatment Centre. World Heal Organ Publ. 2020;(March):120.

12. Rutala WA, Weber DJ. Disinfection and Sterilization in Health Care Facilities: What Clinicians Need to Know [Internet]. https://doi.org/10.1086/423182.PMid:15356786 